\title{
Design and results of the USA-Mexico Border Human Papillomavirus (HPV), Cervical Dysplasia, and Chlamydia trachomatis Study
}

\author{
Anna R. Giuliano, ${ }^{1}$ Catalina Denman, ${ }^{2}$ Jill Guernsey de Zapien, ${ }^{1,3}$ \\ Jose Luis Navarro Henze, ${ }^{4}$ Luis Ortega, ${ }^{5}$ Bogomil Djambazov, ${ }^{5}$ \\ Elena Mendez Brown de Galaz, ${ }^{6}$ and Kenneth Hatch ${ }^{7}$
}

ABSTRACT Objective. Mexico has one of the highest mortality rates of invasive cervical cancer in the world. This is particularly true for the states in northern Mexico that border on the United States of America. In addition, Hispanics in the United States have higher rates than do non-Hispanics in the country. Therefore, a binational team was formed to focus on this problem and to determine the risk factors and prevalence of cervical dysplasia and human papillomavirus (HPV) infection, the sexually transmitted disease (STD) known to cause cervical cancer. Chlamydia trachomatis infection, a common STD and potential HPV cofactor, was also assessed.

Methods. Research was conducted in 1997 and 1998 in the border region of two states, Arizona in the United States and Sonora in Mexico, applying a cross-sectional study of women attending clinics for routine gynecologic care. Clinical measurements included Pap smears, $H P V$ infection by both polymerase chain reaction (PCR) and Hybrid Capture (HC), and C. trachomatis status by HC and enzyme-linked immunoassay (EIA). A total of 2436 women were enrolled (mean age 33.3 years \pm 10.3 years).

Results. The overall prevalence of abnormal cytology was $9.3 \%$, with a significant difference in the prevalence in Mexico (11.4\%) vs. the United States (6.6\%). Of the participants, $14.5 \%$ of them tested positive for HPV by PCR, with no significant difference between the two countries, in spite of a lower behavioral risk profile for the Mexican women. Overall prevalence of C. trachomatis was found to be greater by HC than by EIA ( $8.2 \%$ vs. 3.0\%), and in Mexico higher by both methods.

Conclusions. An important accomplishment of the project was the implementation of a quality control program for Pap smear collection, which resulted in a significant reduction in inadequate smears in Mexico. Despite numerous potential logistical barriers, the binational team successfully conducted a large-scale study in the border area and developed an infrastructure for future research.

Key words Human papillomavirus, cervical cancer, Chlamydia trachomatis, United States of America, Mexico.

1 University of Arizona, Arizona Cancer Center, Tucson, Arizona, United States of America. Address correspondence and reprint requests to: Anna Giuliano, Arizona Cancer Center, University of Arizona, 1515 N. Campbell Ave., Room 4977C, Tucson, Arizona 85724-5024, United States of America; telephone: 520-626-3341; fax: 520-626-3343; e-mail: agiuliano@azcc.arizona.edu
2 El Colegio de Sonora, Hermosillo, Sonora, Mexico. 3 University of Arizona, Rural Health Office, Tucson, Arizona, United States of America.

4 Secretaría de Salud Pública de Sonora, Hermosillo, Sonora, Mexico.

5 Arizona Department of Health Services, Phoenix, Arizona, United States of America.
6 Instituto de Seguridad Social al Servicio de los Trabajadores del Estado-ISSSTE, Hermosillo, Sonora, Mexico.

7 University of Arizona, Department of Obstetrics and Gynecology, Tucson, Arizona, United States of America. 
Invasive cervical cancer comprises $11.6 \%$ of all cancers among women worldwide and is the second most common cancer that they experience. Latin America has one of the highest cervical cancer incidence rates in the world, with an age-adjusted incidence of 40.8/100 000, far above the ageadjusted incidence of 9.5/100 000 in North America (1). Cervical cancer remains one of the most important health problems in developing countries such as Mexico. It is also a major concern among minority populations in the United States of America, whose incidence of cervical cancer (17.1/100 000) is significantly elevated in comparison to the rate for non-Hispanic whites in the country (7.5/100 000) (2).

Mexico has one of the highest invasive cervical cancer incidence and mortality rates in the world, with one death from cervical cancer approximately every 2 hours (3), a mortality rate of 5.2/100 000 (4), and an incidence rate of $45 / 100000 .^{8}$ In general, higher cervical cancer mortality rates in Mexico are found among those states with the lowest socioeconomic status. While not among the poorer states in Mexico, the states in northern Mexico that border the United States have a significantly higher cervical cancer mortality rate than does Mexico City (3). As with other minority populations in the United States, Hispanics suffer disproportionately from invasive cervical cancer, with higher incidence and mortality rates than among non-Hispanic whites in the country (2). While the exact incidence of cervical cancer in the United States-Mexico border area is unknown, the existing data suggest that the rate is higher than that for the interior of both countries, respectively.

Evidence from epidemiological studies conducted around the world clearly indicates that human papillomavirus

\footnotetext{
Herrero R, Muñoz N, Lazcano E, Posso $\mathrm{H}$ Sukvirach S, de Sanjosé S, et al. HPV international prevalence surveys in general populations. Paper presented at 18th International Papillomavirus Conference, July 2000, Barcelona, Spain.
}

(HPV) infection is a cause of cervical cancer (5). Strong and consistent associations have been noted for oncogenic HPV types and invasive cervical cancer. While HPV infection is the most common sexually transmitted infection, relatively few women develop clinical lesions or cervical cancer. These data suggest that HPV is a necessary but insufficient cause of cervical cancer. Prevalence of specific types of HPV is known to vary in different regions of the world, as do the factors that may inhibit or promote HPV carcinogenesis (5). To date, no studies of HPV infection and other sexually transmitted diseases, such as infection with Chlamydia trachomatis, a potential HPV cofactor, have been conducted in the United StatesMexico border area.

The border states of Arizona in the United States and Sonora in Mexico have a history of more than 30 years of collaboration on public health issues through two commissions, the United States-Mexico Commission and the Sonora-Arizona Commission. In addition, there has been a long history of collaboration among other academic and nongovernmental organizations in Arizona and Sonora. This collaboration has been very important in terms of building strong working relationships around common issues that impact both states. In the past 6 years additional efforts have resulted in the identification of some specific common health issues for research and intervention, with STDs and cervical cancer being priorities.

In 1995 the Cervical Cancer Binational Technical Team was formed to focus specifically on research related to cervical cancer and C. trachomatis. To address the need for information regarding the prevalence and risk factors for cervical dysplasia and cancer, the group designed and implemented a study in the Arizona-Sonora border area. In this manuscript we describe the design, methods, and results of the USA-Mexico Border Human Papillomavirus (HPV), Cervical Dysplasia, and Chlamydia trachomatis Study. In a previous publication (6) a description of the binational collaboration process is provided.

\section{METHODOLOGY}

\section{Study design}

A cross-sectional survey was conducted from January 1997 to June 1998, recruiting women aged 15 years and older living in three pairs of contiguous Arizona-Sonora border communities and areas near them: DouglasAgua Prieta, Nogales-Nogales, and Yuma-San Luis Río Colorado. In addition, Tucson, Arizona, and Hermosillo, Sonora, were included as they are the major city centers closest to the border in each of the respective states.

Laboratory measurements included HPV infection by polymerase chain reaction (PCR) and Hybrid Capture, C. trachomatis status by enzyme-linked immunoassay (EIA) and Hybrid Capture, and cytology results. In addition to the clinical measurements, study participants completed a risk factor questionnaire that assessed reproductive, sexual and medical histories, and demographic data.

\section{Population}

The study population consisted of women aged 15 years or older receiving routine gynecological care in borderarea locations of Arizona and Sonora. The participants in Arizona were recruited from women attending family planning clinics at community health centers operated by nonprofit groups and at clinics operated by the local affiliate of the national nonprofit Planned Parenthood organization. The four Arizona locations were: Douglas, Bisbee, and Sierra Vista in Cochise County; Nogales in Santa Cruz County; Yuma in Yuma County; and Tucson in Pima County. The Arizona clinics in our study served primarily Hispanic women in the eligible age range for this study.

The Sonora, Mexico, participants were recruited from public health clinics that are part of that state's Secretariat of Public Health system. The Sonora locations were: Agua Prieta, Nogales, San Luis Río Colorado, and Hermosillo; 
also included was Cananea, which is approximately equidistant from Agua Prieta and Nogales.

The three Arizona-Sonora border sister city areas we selected all have unique characteristics. The NogalesNogales area is one of the most important border crossing points for commerce between the United States and Mexico, and Nogales, Mexico, has over 60 maquiladora plants, where imported parts are assembled into products for export. The San Luis Río Colorado and Yuma area is the site of the largest agricultural production and farm worker population at the Arizona-Sonora border. Finally, the Douglas-Agua Prieta region is the smallest and most rural of these three sister city areas; it is an important mining area. The research group agreed that in order to have a representative sample from the Arizona-Sonora border all three areas needed to be included. Additionally, Hermosillo and Tucson were selected as similar large urban centers in the two states that are heavily influenced by their proximity to the border.

\section{Participant eligibility}

Participants were women who selfreferred to community health centers and Planned Parenthood clinics in Arizona, and public health clinics in Sonora, for routine gynecological care. We invited women to participate in this study who were: a) 15 years of age or older, b) residents of the ArizonaSonora border areas or of Hermosillo or Tucson, c) not pregnant, and d) still having menstrual periods (e.g., no hysterectomy).

\section{Participant recruitment}

Four bilingual female interviewers in Arizona and four female interviewers in Sonora worked in the participating study clinics. The interviewers worked closely with the clinics' staff members to identify all women who had made appointments for routine gynecological care each day, and who met the study eligibility age criteria. When meeting the client, the interviewer explained to her the nature of the study and asked about her willingness to participate. Following the routine Pap smear, each participant would have to complete a questionnaire, have a second cervical smear taken for HPV analyses, and have a third smear taken for C. trachomatis determination. If the client was interested, the research interviewer carefully explained the study, and the participant completed an informed consent form that had been approved by the institutional review boards of the University of Arizona, the Arizona Department of Health Services, the Secretariat of Public Health of Sonora, and the Colegio de Sonora. The number of women approached for participation, the number refusing to participate, and their reasons for not participating were kept in a log updated daily by each research interviewer.

\section{Study protocol}

The study participants completed an interviewer-administered questionnaire that assessed established risk factors for HPV infection, C. trachomatis infection, and cervical cancer. Experience from extensive focus group sessions and piloting of the questionnaire among the target population indicated that women were most comfortable and most willing to provide detailed information on sensitive topics if there was a trusting relationship with the interviewer. To facilitate this rapport, the questionnaire was administered by the interviewer in the language that the respondent chose, either Spanish or English.

After the Pap smear was obtained for routine clinical purposes, two additional samples of exfoliated cervical cells were obtained, for the analyses of HPV DNA and for C. trachomatis detection.

By mail, we sent all the study participants notification of their HPV and cytology results, with an accompanying explanation of these results and recommendations for scheduling of future Pap smears. Women were also notified if they tested positive for C. trachomatis.
In Mexico the Secretariat of Public Health of Sonora provided follow-up on positive $C$. trachomatis results.

\section{Cytology}

Development of a common scheme for reporting/recording Pap smears: pilot validation study. Before we began the main body of our research, we worked to determine the degree of concordance in cytology reporting between pathologists in Mexico and the United States. This was especially important given that the two countries utilize different diagnostic reporting schema. This preliminary step was a way to discover any patterns of diagnostic discordance, and, as needed, develop a consensus on them.

One hundred Pap smear slides collected in Mexico were rescreened in a blinded fashion by a pathologist from the University of Arizona. The diagnoses of the Pap smear slides were recorded per criteria as outlined in the Bethesda System for reporting cervical/vaginal cytologic diagnoses (7), and included evaluation of specimen adequacy. Evaluation of the specimen adequacy included: 1) amount of wellpreserved and well-visualized squamous epithelial cells, 2) presence and amount of the endocervical/transformation zone component, 3) the degree (if any) of obscuring blood or inflammation, and 4) presence of air-drying artifact. With respect to specific diagnoses, a simplified set of five categories was established to reflect the need for clinical follow-up. This was done to derive data regarding diagnostic concordance between the two countries. The diagnostic categories were: 1) normal/inflammation, 2) atypical squamous cells of undetermined significance (ASCUS) / atypical glandular cells of undetermined significance (AGUS), 3) low-grade squamous intraepithelial lesion (HPV effect/mild dysplasia), 4) high-grade squamous intraepithelial lesion (moderate dysplasia/severe dysplasia/carcinoma in situ), and 5) squamous cell carcinoma. The degrees of diagnostic agreement/disagreement were reported numerically from 0 to 4 , 
with 0 representing complete diagnostic agreement and 4 indicating maximum disagreement.

Through the process of validation, several findings were made. First, 70\% of the Mexican specimens were not optimal due to the lack of endocervical cells on the smear. These were categorized as "satisfactory but limited by absence of endocervical cells" per the Bethesda System criteria for specimen adequacy. This finding clearly pointed to a need for standardization of specimen collection between the United States and Mexico. Upon further discussion, it was determined that in Sonora, the public health clinics collected cells for Pap smears using a tongue depressor that had been broken in half. Specific sampling of the endocervix was not performed. Thus, prior to onset of the study, health care professionals in Mexico at the clinic study sites were trained by members of the Department of Obstetrics and Gynecology at the University of Arizona and the Social Security and Services Institute for Government Employees Hospital, Hermosillo, Sonora, Mexico, in the technique of Pap smear collection as established in the United States. This technique included sampling of the ectocervix using a wooden Ayre spatula and sampling of the endocervix with a cytobrush.

Pilot validation study results. Of the 100 Pap smear slides collected in Mexico, 35 of them were discordant in their reading by the Mexican pathologists and the United States pathologist. Of these 35,23 of them (65\%) were a consequence of differences in reporting of HPV in Mexico and in the United States. Specifically, in the United States HPV, or koilocytotic atypia, is categorized under the rubric of lowgrade squamous intraepithelial lesion (LGSIL). In Mexico, however, if HPV is the only abnormal finding (with no concomitant squamous dysplasia), the smear is reported as normal, with a comment stating the presence of viral changes. This discordance was considered a semantic issue rather than discordance based upon true disagree- ment between actual cytologic observations. However, given the fact that HPV analyses of the study participants were planned, the decision was made to include HPV as part of the diagnosis rather than as a part of a comment.

Of the remaining 12 discrepant cases, 6 of them had a discordance of 1 . Of these 6, 1 was diagnosed as mild dysplasia by Mexico and as ASCUS by the United States. Another of the 6 was reported as ASCUS by the United States and normal by Mexico. The remaining 4 of the 6 specimens with 1 degree of discordance were reported as moderate dysplasia by Mexico and as LGSIL by the United States. Of the 6 remaining cases with a discordance greater than 1,5 of the cases had a discordance of 2 and the other case had a discordance of 3 . With the discordance of 2, 4 were diagnosed as mild dysplasia by Mexico and as normal/inflammation by the United States. The other case was reported as severe dysplasia by Mexico and as ASCUS by the United States. The case with a discordance of 3 was reported as moderate dysplasia by Mexico and as normal by the United States. This most-discordant specimen was reviewed in depth, and it was found to be markedly airdried and thus not optimal for cytologic evaluation.

Overall, the degree of agreement between the two countries with respect to cytologic diagnoses was good, with a kappa value of 0.73 . Due to discordance noted above with the lowgrade lesions, additional collaborative sessions were held to achieve as much consensus as possible between the two countries. Particular emphasis was directed at outlining criteria for the categories of ASCUS and AGUS, neither of which are used in the cervical intraepithelial neoplasia (CIN) grading system, which was developed before the Bethesda System.

An additional finding stemming from the pilot validation study was the observation that 70 of the 100 Pap smear slides from Mexico lacked an endocervical component. This was of particular significance since the transformation zone is the site wherein cervical dysplasia and neoplasia are thought to arise. As such, its absence in a significant number of the smears highlighted several concerns with respect to the Pap smear techniques in Mexico: 1) the need for appropriate tools to sample the cervix, 2) the need for training of health care workers in the proper collection of Pap smears, and 3) the possibility that a significant number of preneoplastic lesions may have been missed due to inadequacy of sampling.

Common scheme coding system. The final cytological coding system that we developed for our study combined elements of both the Bethesda System and the CIN system. The diagnostic categories included specific diagnoses and evaluation of specimen adequacy (Table 1).

TABLE 1. Binational coding system for Pap smear results, Cervical Cancer Binational Technical Team, Sonora, Mexico, and Arizona, United States, 1997-1998

\begin{tabular}{lc}
\hline \multicolumn{1}{c}{ Diagnosis } & Code \\
\hline Normal & 0 \\
Inflammation & 1 \\
Atypical squamous cells of unknown & \\
significance (ASCUS) & 2 \\
$\quad$ ASCUS favor inflammation/reactive & 3 \\
$\quad$ ASCUS favor dysplasia & 4 \\
Atypical glandular cells of unknown & \\
significance (AGUS) & 5 \\
AGUS favor inflammation/reactive & 6 \\
$\quad$ AGUS favor dysplasia & 7 \\
Low-grade squamous intraepithelial & \\
lesion & 8 \\
Cellular changes consistent with HPV & 9 \\
$\quad$ Mild squamous dysplasia & 10 \\
High-grade squamous intraepithelial & \\
lesion & \\
$\quad$ Moderate squamous dysplasia & 11 \\
Severe squamous dysplasia & 13 \\
Carcinoma in situ & 14 \\
Squamous cell carcinoma & 15 \\
Adenocarcinoma & 16 \\
Inadequate specimen & \\
Satisfactory but limited & \\
$\quad$ Unsatisfactory & \\
Satisfactory but limited/negative & 19 \\
$\quad$ Satisfactory but limited/ASCUS & 21 \\
\hline
\end{tabular}


Collection of study pap smears. Following the completion of the pilot validation study and the development of a common scheme, cervical cytology specimens for the main part of our study were collected using the Ayre spatula to sample the ectocervix, and a cytobrush to sample the endocervix/ transformation zone. Healthcare workers in each of the clinic sites received training in the proper collection technique from members of the Department of Obstetrics and Gynecology of the University of Arizona.

Review of study pap smear results. All Pap smear specimens collected from the four sites in the United States were read initially by pathologists in the laboratories with which the particular clinics were affiliated. These laboratories included: PathNet (Van Nuys, California), LabCorp (Phoenix, Arizona), SonoraQuest Laboratories (Phoenix, Arizona), Kino Community Hospital (Tucson, Arizona), Tucson Medical Center (Tucson, Arizona), and SmithKline Beecham (San Jose, California). One study pathologist (Janine Feng, University of Arizona, Department of Pathology) reread the cytology slides from the United States in a blinded fashion, and those diagnoses were reported for the study using the system developed collaboratively.

Pap smears from women enrolled in Mexico were initially read by cytologists in the Sonora State Laboratory of the Secretariat of Public Health. Another study pathologist (EMBG) then rescreened these Pap smears, adhering to the cytology coding system developed for this study (Table 1).

The two study pathologist then both reviewed all of the abnormals and $10 \%$ of the normals from both countries. Quality assurance data from the two countries found interrater agreements of $46.3 \%$ (Mexican review of United States slides, kappa $=0.292$ ) and of 61.7\% (United States review of Mexican slides, kappa $=0.523)$ if all 21 categories delineated in the final, common, binational coding system were used. When the system was condensed to six categories, the interrater agreement in- creased to $57.3 \%$ and $80.1 \%$ (kappas of 0.418 and 0.729$)$, respectively. The major areas of disagreement were in the diagnoses of low-grade lesions and in ASCUS/AGUS categories. Good interrater agreement was noted for the high-grade lesions.

\section{HPV cervical cell collection and detection}

Cervical cells were collected for HPV analysis from the ectocervix and endocervix using a Cytosoft cytology brush and immediately suspended in 0.6 mL ViraType Diagnostics Sample Transport Medium (Digene Corporation, Gaithersburg, Maryland, United States). Following collection, samples were maintained at $4{ }^{\circ} \mathrm{C}$ for a maximum of 2 weeks, until being transported on ice to the University of Arizona laboratory. Samples were then maintained at $-70{ }^{\circ} \mathrm{C}$ until analyzed.

HPV DNA analyses in exfoliated cervical cell samples were conducted using the Hybrid Capture 2 System (Digene Corporation, Gaithersburg, Maryland, United States) and polymerase chain reaction (PCR) from samples obtained during the gynecological examination. All specimens were analyzed by Digene Hybrid Capture 2 technology using the high-risk probe, which is designed to detect oncogenic HPV types 16, 18, 31, 33, 35, $39,45,51,52,56,58,59$, and 68 . The Hybrid Capture 2 technology is a signal amplified hybridization antibody capture microplate assay (8). It utilizes chemiluminescent detection in which the presence of HPV is detected by light emitted and then measured as relative light units (RLUs). An RLU positive control ratio of $\geq 1$ is regarded as HPV-positive for one or more of the above-mentioned oncogenic HPV types. Specimens with RLU cutoff value ratios $<1$ are considered "negative" or "nondetected." The sensitivity of the test is 1 picogram of viral DNA per $100 \mu \mathrm{L}$. To ensure that samples were accurately classified, those samples testing with an RLU ratio of 1.0-2.0 were retested two subsequent times by Hybrid Capture. Only sam- ples that had RLU ratios greater than 1.0 on two of the three tests were classified as HPV-positive by the Hybrid Capture method. The low-risk probe was not utilized in this study, and so nononcogenic HPV types were not detected using the Hybrid Capture 2 method.

HPV detection was also conducted using PCR with all the cervical cell samples collected. Genomic DNA was extracted following standard techniques. $(9,10)$. In brief, $50-\mu \mathrm{L}$ aliquots were digested with $5 \mu \mathrm{L}$ Proteinase $\mathrm{K}$ for $1 \mathrm{~h}$ at $65^{\circ} \mathrm{C}$, followed by $5 \mathrm{M}$ ammonium acetate and ethanol precipitation. The crude DNA pellet was dried and resuspended in $50 \mu \mathrm{L} 10 \mathrm{mM}$ Tris, $\mathrm{pH}$ 7.5. The DNA extracts were then stored at $-80{ }^{\circ} \mathrm{C}$ until amplification. Specimens were tested for the presence of HPV by amplifying $5 \mu \mathrm{L}$ of the DNA extracts with the PGMY09/11 L1 consensus primer system (9) and AmpliTaq Gold polymerase (PerkinElmer, Foster City, California). In brief, each amplification contained $10 \times$ PCR Buffer II, $25 \mathrm{mM} \mathrm{MgCl} 2,200 \mu \mathrm{L}$ (each) dCTP, dGTP, and dATP, $600 \mu \mathrm{L}$ dUTP, $5 \mathrm{U}$ of AmpliTaq Gold, $50 \mu \mathrm{M}$ of PGMY09, $50 \mu \mathrm{M}$ of PGMY09, $50 \mu \mathrm{M}$ PGMY11, $50 \mu \mathrm{M}$ of B_PC04, $50 \mu \mathrm{M}$ of B_GH20, and $5 \mu \mathrm{L}$ of the template. For eventual inclusion of uracil- $\mathrm{N}$-glycosylase to prevent product carryover, dTTP was replaced with dUTP. To determine specimen adequacy, the GH20/PC04 human $\beta$-globin target was coamplified with the HPV consensus primers. For every 10 samples a negative control $\left(\mathrm{H}_{2} \mathrm{O}\right)$ and a positive control (CaSki cells) were run to control for contamination and accuracy.

The samples were amplified using the GeneAmp PCR System 9700 (Perkin-Elmer, Foster City, California). The following amplification profile was used: $95{ }^{\circ} \mathrm{C}$ hot start for $9 \mathrm{~min}$, $95^{\circ} \mathrm{C}$ denaturation for $1 \mathrm{~min}, 55^{\circ} \mathrm{C}$ annealing for $1 \mathrm{~min}$, and $72{ }^{\circ} \mathrm{C}$ extension for $1 \mathrm{~min}$ for 40 cycles; this was followed by a 5 -min terminal extension at $72{ }^{\circ} \mathrm{C}$ and a hold step at $4{ }^{\circ} \mathrm{C}$.

HPV genotyping was conducted using the reverse line blot method (10) on all samples that were positive by PCR. This detection method utilizes 
the HPV L1 consensus PCR products labeled with biotin to detect $27 \mathrm{HPV}$ types. The HPV genotype strip contains 29 probe lines, 27 for individual HPV genotypes and 2 with concentrations of the $\beta$-globin control probe. The following types are detected: $6,11,16$, $18,26,31,33,35,39,40,42,45,51$ to 59, 66, 68, MM4, MM7, MM8, and MM9. Briefly, the PCR products labeled with biotin were denatured and added to the probe strip in a hybridization buffer. After strips were washed, streptavidin-horseradish peroxidase was added to facilitate detection of the various HPV types. After final wash, buffer was removed by vacuum aspiration, and strips were rinsed in $0.1 \mathrm{M}$ sodium citrate. Color development was activated by incubation in a mixture of hydrogen peroxide in sodium citrate buffer and tetramethylbenzidine in dimethylformamide for $5 \mathrm{~min}$ on a rotating platform (70 rpm). Developed strips were interpreted and photographed for future reference. Strip interpretation was performed with a labeled overlay, with lines indicating the position of each probe relative to the reference mark.

The oncogenic HPV types associated with cervical dysplasia and cancer include 16, 18, 31, 33, 35, 39, 45, 51, 52, 55, 56, 58, 59, 68, 26, MM4, MM7, and MM9. The nononcogenic types detected are 6, 11, 40, 42, 53, 54, 57, 66, and MM8. Furthermore, there are five oncogenic HPV types (26, 55, 73, MM4, and MM7) detected by PCR that are not included in the Hybrid Capture 2 high-risk probe.

\section{C. trachomatis cell collection and detection}

Following cervical sampling for cytology and HPV analyses, specimens for C. trachomatis analysis were collected from the endocervical os or the cervical canal, using a cotton swab. The cell specimens were placed in transport medium and sent for analysis by enzyme-linked immunoassay (EIA).

C. trachomatis testing was originally conducted at the Arizona Department
TABLE 2. Reasons for nonparticipation by women approached for study, Cervical Cancer Binational Technical Team, Sonora, Mexico, and Arizona, United States, 1997-1998

\begin{tabular}{lrc}
\hline \multicolumn{1}{c}{ Status/Reason } & No. & \% of 2 626 women approached \\
\hline Eligible & & \\
$\quad$ Refused participation, no reason & 113 & 4.3 \\
"Survey too personal" & 3 & 0.1 \\
"Too old" & 5 & 0.2 \\
Bleeding, no sample taken & 21 & 0.8 \\
Ineligible & & \\
Pregnant & 21 & 0.8 \\
Hysterectomy & 8 & 0.3 \\
Other & 19 & 0.7 \\
\hline
\end{tabular}

of Health Services (ADHS) laboratory using the EIA method. During the first half of the study, analysis was performed using Chlamydia Microplate EIA (Sanofi Diagnostics Pasteur, Inc., Chaska, Minnesota, United States); during the second half of the study, Chlamydiazyme EIA (Abbott Laboratories, Inc., North Chicago, Illinois, United States) was used. Specimen collection, transport, and analysis were performed in accordance with the manufacturers' instructions. All positive results were confirmed within $48 \mathrm{~h}$ by the blocking assay procedure.

C. trachomatis testing was also conducted using the CT-ID Hybrid Capture II (Digene Corporation, Gaithersburg, Maryland, United States) test at the University of Arizona laboratory. Like the Hybrid Capture 2 test for HPV analysis, this test is a signal amplified hybridization microplate assay that utilizes chemiluminescence for qualitative detection of $C$. trachomatis DNA. In addition, the $C$. trachomatis probe contains a mixture specifically chosen to eliminate cross-reactivity with DNA sequences from human cells, other bacterial species, and chlamydia species other than trachomatis. The endocervical and ectocervical specimens collected for HPV detection, described above, were used for this second $C$. trachomatis analysis.

\section{RESULTS}

\section{Participant recruitment and response rates}

A total of 2626 women were approached for recruitment and were initially screened for eligibility for the study. There were 2578 women identified in this manner who met the study eligibility criteria, and 2436 of these women were enrolled in the study. The overall response rate was $92.8 \%$. Reasons for nonparticipation are shown in Table 2.

Table 3 shows the number of completed questionnaires and clinical lab-
TABLE 3. Completed study results by country, Cervical Cancer Binational Technical Team, Sonora, Mexico, and Arizona, United States, 1997-1998

\begin{tabular}{lccc}
\hline & Mexico & United States & Total \\
\hline Questionnaire & 1399 & 1037 & 2436 \\
HPV (Hybrid Capture) & 1304 & 1015 & 2319 \\
HPV (PCR) & 1258 & 988 & 2246 \\
Cytology & 1257 & 980 & 2237 \\
Chlamydia (EIA) & 1033 & 947 & 1980 \\
Chlamydia (Hybrid Capture) & 1285 & 985 & 2270 \\
\hline
\end{tabular}


oratory results. Survey questionnaires were completed by 1399 women from Sonora, Mexico, and 1037 from Arizona, United States. There were fewer C. trachomatis analyses completed with EIA than with Hybrid Capture, for reasons that included problems with transport of samples across the border and arrival and analysis of samples beyond the 5-day window for analyses utilizing the EIA method. Similarly, cytology results were unavailable for 199 women. Reasons for lack of cytology results included: samples were not obtained at the clinical visit, samples were unavailable for retrieval in Mexico, and samples were inadequate for evaluation. Seventy-three fewer PCR HPV results were available compared to Hybrid Capture HPV results due to the following reasons: inadequate sample (18 samples), unevaluable PCR due to 1 or 0 globin bands or lack of double stranded DNA (19 samples), and samples being sent to a reference laboratory for other analyses and thus not available for PCR testing (36 samples).

\section{Selected characteristics of participants}

Selected demographic and health characteristics are provided by country of enrollment in Table 4 . The mean age of participants was 33.3 years \pm 10.3 years. Mexican women were significantly older than the women in the United States $(P<0.001)$. Of the women in the United States, just over three-quarters of them were MexicanAmerican. Overall, fewer than 30\% of the women had completed high school, with the women in the United States reporting a higher level of education than the women in Mexico. Sexual and reproductive histories differed significantly between the two countries. Women in the United States reported a lower age at first intercourse and a higher number of male sexual partners during their lifetime. Mexican women had more live births per woman and slightly lower oral contraceptive use. While only 53\% of the entire study population had been screened by Pap smear in the preceding year, $87 \%$ of them had received screening in the preceding 3 years.

\section{Prevalence of HPV and chlamydia infections and abnormal cytology}

Pap smears were collected from 2237 of the 2436 women enrolled in the study, 17 of which resulted in inadequate/unsatisfactory specimens. Diagnoses were therefore available for 2220 women (91.1\%). Table 5 shows the age-adjusted prevalence of abnormal cytology by country. To control for the statistical differences in ages of Mexican and United States women, the population distribution of the entire study sample was used as an estimate of the standard population. The overall prevalence of abnormal cytology in this population was $9.3 \%$. Significant differences in the age-adjusted prevalence of abnormal cytology were found between Mexico (11.4\%) and United States (6.6\%).

Table 5 also shows the HPV infection rates as determined by the two independent laboratory testing procedures, Hybrid Capture and PCR. Using the Hybrid Capture high-risk probe, $15.5 \%$ overall were HPV-positive, with no significant difference between the countries. Using PCR, 14.5\% overall were positive for any HPV type, with a nonsignificant higher rate in the United States (15.1\%) than in Mexico $(13.8 \%)(P=0.405)$. Approximately $83 \%$ of the HPV infections observed were infections with oncogenic-type viruses. The prevalence of oncogenic HPV was higher in the United States (12.8\%) than in Mexico $(11.3 \%)$, but the difference was not significant. No significant differences in prevalence of nononcogenic HPV were observed by country.

As explained earlier, C. trachomatis infection was determined using two independent procedures, EIA and Hybrid Capture. Tremendous differences in C. trachomatis prevalence were found with the two methods. Using Hybrid Capture, $8.2 \%$ of study participants were positive for $C$. trachomatis, with a significantly higher prevalence noted in Mexico (9.7\%) than in the United States $(6.7 \%)$ when controlling for age $(P=0.013)$. In contrast, using EIA, only $3.0 \%$ of the participants overall were positive, with an age-adjusted prevalence of $4.4 \%$ in Mexico and of $1.3 \%$ in the United States.

\section{DISCUSSION}

This is the first study to examine prevalence of HPV, C. trachomatis, and cervical dysplasia among women living in the United States-Mexico border area. Despite numerous logistical barriers to working binationally, which we have previously discussed (6), we successfully recruited and interviewed 2436 women. Through this effort we developed an infrastructure with which to conduct future epidemiological studies of sexually transmitted diseases and cervical cancer.

Even though Mexican women had an overall lower behavioral risk profile for STDs, they had significantly higher rates of $C$. trachomatis in comparison to United States women. There were similar rates of oncogenic HPV infection in both groups. As expected, given the high incidence of invasive cervical cancer in Mexico, significantly higher rates of abnormal cytology were observed in Mexico than in the United States. Studies such as these are important in understanding the factors associated with cervical cancer and the programs that are needed for this region to reduce the disproportionately high rates of the disease.

One of the more important findings to emerge from this study is the problem associated with the lack of appropriate tools for implementing the Pap smear in public health clinics in Sonora. Results from the pilot cytology validation study that we conducted before the main body of our research indicated that most Pap smears obtained under routine clinical conditions in Sonora were lacking endocervical cells and had to be considered inadequate. Similar results have been found by other studies evaluating the quality of the Pap smear screening program in Mexico, with one of the 
TABLE 4. Distribution of selected characteristics of participants by country, Cervical Cancer Binational Technical Team, Sonora, Mexico, and Arizona, United States, 1997-1998

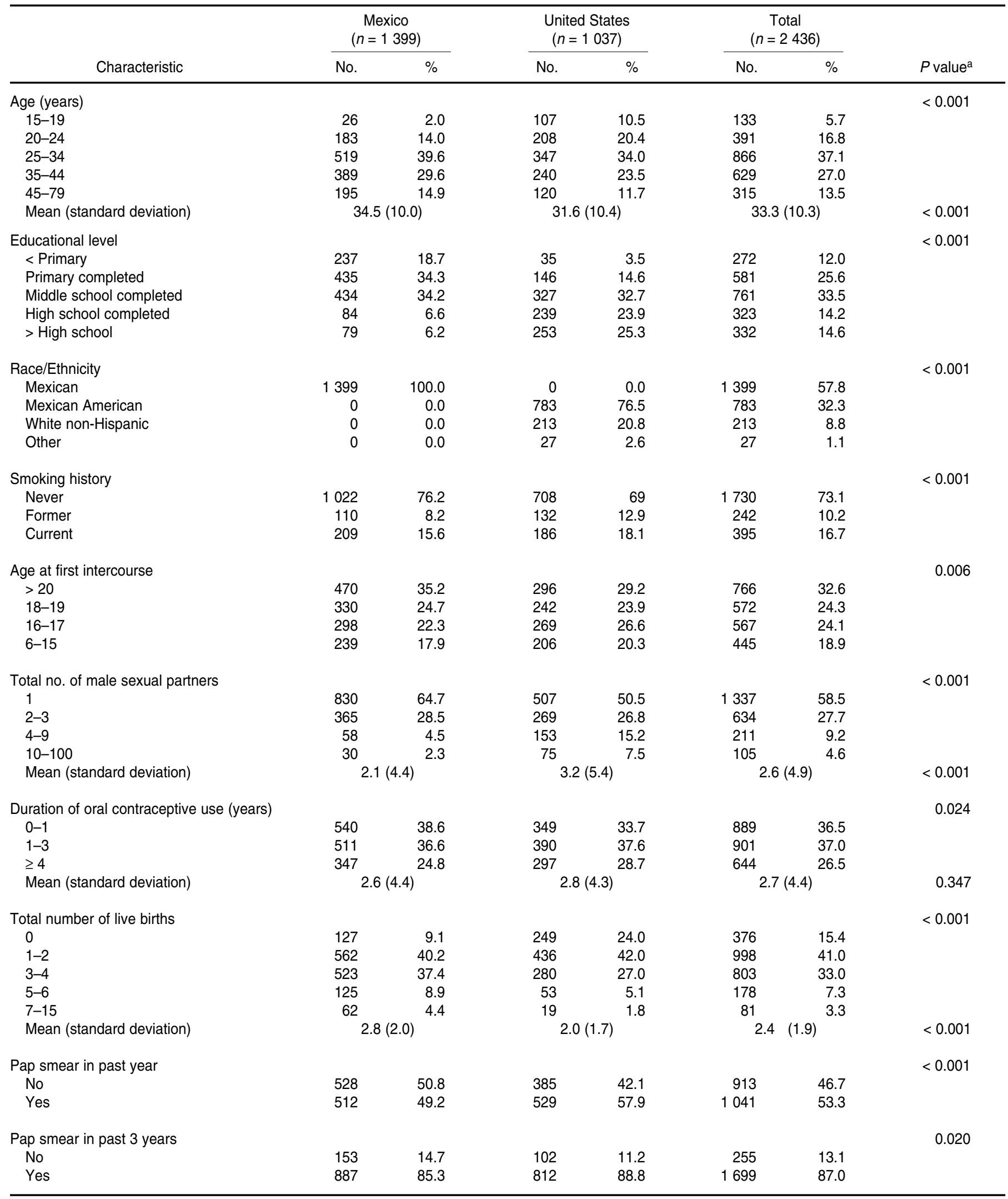

a $P$ value is for difference between Mexico and the United States. 
TABLE 5. Age-adjusted prevalence (\% and $95 \%$ confidence interval) of abnormal cytology, of HPV, and of Chlamydia trachomatis, by country, Cervical Cancer Binational Technical Team, Sonora, Mexico, and Arizona, United States, 1997-1998

\begin{tabular}{|c|c|c|c|c|c|c|}
\hline & \multicolumn{2}{|c|}{ Overall } & \multicolumn{2}{|c|}{ Mexico } & \multicolumn{2}{|c|}{ United States } \\
\hline & No. & $\%$ & $\%$ & $95 \% \mathrm{Cl}$ & $\%$ & $95 \% \mathrm{Cl}$ \\
\hline Abnormal cytology & 206 & 9.3 & 11.4 & $9.5-13.2$ & 6.6 & $5.0-8.2$ \\
\hline \multicolumn{7}{|l|}{ HPV } \\
\hline $\begin{array}{l}\text { Hybrid Capture } \\
\text { PCR }\end{array}$ & 359 & 15.5 & 15.5 & $13.4-17.7$ & 15.2 & $13.0-17.4$ \\
\hline All types & 325 & 14.5 & 13.8 & $11.7-15.9$ & 15.1 & $12.9-17.3$ \\
\hline Oncogenic type & 270 & 12.1 & 11.3 & $9.4-13.2$ & 12.8 & $10.7-14.9$ \\
\hline Nononcogenic type & 42 & 1.9 & 1.8 & $0.9-2.7$ & 2.2 & $1.2-3.1$ \\
\hline \multicolumn{7}{|l|}{ Chlamydia trachomatis } \\
\hline $\mathrm{EIA}$ & 59 & 3.0 & 4.4 & $2.8-6.0$ & 1.3 & $0.6-2.0$ \\
\hline Hybrid Capture & 185 & 8.2 & 9.7 & $7.8-11.5$ & 6.7 & $5.2-8.2$ \\
\hline
\end{tabular}

studies (11) showing $64 \%$ of samples lacking endocervical cells, and cytopathology laboratories presenting overall false negative rates of $10 \%$ to $54 \%$. We implemented a quality control program in our study that spanned the spectrum of obtaining, fixing, staining, transporting, and diagnosing smears. This program resulted in a dramatic reduction of inadequate smears in Mexico, from $70 \%$ to $9.8 \%$, and a considerable improvement in the reliability of cytology readings. Our experience supports what others (3) have suggested should occur on a national level in countries faced with a high incidence and mortality of cervical cancer. While we were able to improve the quality of the Pap smear screening program in Sonora during the course of the study, repeated quality control measures would need to occur to ensure that these gains in precision and reliability were maintained under normal clinical conditions.
In this study we found an overall HPV prevalence of $14.5 \%$ by PCR and $12.1 \%$ infection with oncogenic HPV types among the participating women. There was no significant difference between Mexico and the United States in the prevalence of oncogenic HPV types. The prevalence of HPV infection in this study is similar to the rates reported for other Mexican populations (4) and for Mexican-American populations (12).

Recent studies suggest that given the high rate of infection in young women, HPV testing of the general population would not be useful clinically, but instead should be used as a method for triaging women presenting with ASCUS and LGSIL (13). This method of reflex HPV testing would have tremendous implications for the Pap smear screening interval currently recommended in Mexico and the United States. One of the criticisms directed toward the Mexican national
Pap smear screening program has been that it focuses needless annual and biennial screening on low-risk groups and inadequately screens highrisk groups. Reflex HPV testing could provide an objective measure of risk from which to determine screening and postscreening guidelines.

Building on the results of this study, we are now evaluating risk factors for abnormal cytology, including a thorough examination of type-specific HPV infection and sexual and reproductive factors as they relate to the utility of HPV testing in this border population. Such information may be useful in identifying innovative methods of cervical cancer prevention, including an efficacious HPV vaccine.

Acknowledgments. This project was supported in part by grants from the Arizona Disease Control Research Commission and from the United States $\mathrm{Na}-$ tional Cancer Institute (KO7-CA60885). This study could not have been conducted without the hard work and dedication of the following individuals and institutions: Eva Moncada, Jennifer Stephan, Janine Feng, Mary Papenfuss, Martha Abrahamsen, Susie Baldwin, Mirna Gutierrez, Magdy Nour, Francisco Garcia, and the Cervical Cancer Binational Technical Team, which consisted of: Hospital Básico units in Nogales, Agua Prieta, Cananea, and San Luis Río Colorado, Sonora, Mexico; Centro Avanzado de Atención Primaria a la Salud, Hermosillo, Sonora, Mexico; Mariposa Community Health Center, Valley Health Center, Cochise County Health Department, Pima County Health Department, and Planned Parenthood of Southern Arizona, Arizona, United States of America.

\section{REFERENCES}

1. Parkin DM, Pisani P, Ferlay J. Estimates of worldwide incidence of 18 major cancers in 1985. Int J Cancer 1993;54:594-606.

2. Miller BA, Kolonel LN, Bernstein L, Young, Jr. JL, Swanson GM, West D, et al., eds. Racial/ ethnic patterns of cancer in the United States 1988-1992. Bethesda, Maryland, United States of America: National Cancer Institute; 1996. (NIH Pub. No. 96-4104).

3. Lazcano-Ponce EC, Rascone-Pacheco RA, Lozano-Ascencio R, Velasco-Mondragon HE. Mortality from cervical carcinoma in Mexico: impact of screening 1980-1990. Acta Cytol 1996;40:506-512.
4. Torroella-Kouri M, Morsberger S, Carrillo A, Mohar A, Meneses A, Ibarra M, et al. HPV prevalence among Mexican women with neoplastic and normal cervixes. Gynecol Oncol 1998;70(1):115-120.

5. International Agency for Research on Cancer. Human papillomaviruses. Lyon, France: IARC; 
1995. (IARC Monographs on the Evaluation of the Carcinogenic Risks to Humans, Vol. 64).

6. Denman CA, Guernsey de Zapien J, Coe K, Navarro-Henze JL, Giuliano AR, Stephan J, et. al. The problem of invasive cervical cancer along the US-Mexico border; planning and implementation of a binational research project. Women and Cancer 1999/2000;1:45-50.

7. The 1988 Bethesda System for reporting cervical/vaginal cytological diagnoses. National Cancer Institute Workshop. JAMA 1989; 262(7): 931-934.

8. Cox JT, Lorincz AT, Schiffman MH, Sherman ME, Cullen A, Kurman RJ. Human papillomavirus testing by hybrid capture appears to be useful in triaging women with a cytologic diagnosis of atypical squamous cells of undetermined significance. Am J Obstet Gynecol 1995;172(3):946-954.
9. Gravitt PE, Peyton CL, Alessi TQ, Wheeler CM, Coutlee F, Hildesheim A, et al. Improved amplification of genital human papillomaviruses. J Clin Microbiol 2000;38:357-361.

10. Gravitt PE, Peyton CL, Apple RJ, Wheeler CM. Genotyping of 27 human papillomavirus types by using L1 consensus PCR products by a single-hybridization, reverse line blot detection method. J Clin Microbiol 1998;36: 3020-3027.

11. Lazcano-Ponce EC, Najera-Aguilar P, Buiatti E, Alonso-de-Ruiz P, Kuri P, Cantoral L, et al. The cervical cancer screening program in Mexico: problems with access and coverage. Cancer Causes Control 1997:8:1-7.

12. Giuliano AR, Papenfuss M, Schneider A, Nour M, Hatch K. Risk factors for high risk type human papillomavirus infection among Mexican American women. Cancer Epidemiol Biomarkers Prev 1999;8:615-620.
13. Koutsky LA, Atypical Squamous Cells of Undetermined Significance/Low Grade Squamous Intraepithelial Lesions Triage Study (ALTS) Group. Human papillomavirus testing for triage of women with cytologic evidence of low-grade squamous intraepithelial lesions: baseline data from a randomized trial. J Natl Cancer Inst 2000;92(5):397-402.

Manuscript received 10 October 2000 and accepted for publication on 29 January 2001.

RESUMEN Objetivos. México tiene una de las mayores tasas mundiales de mortalidad por cáncer cervical invasor, sobre todo en los estados del norte que tienen frontera con los Estados Unidos de América (EE.UU.). Además, los hispanos residentes en los EE.UU. tienen mayores tasas que los no hispanos de este país. Considerando esta situación, se formó un equipo de ambos países para analizar el problema y determinar la prevalencia y factores de riesgo de la displasia cervical y de la infección por papilomavirus humanos (PVH), una enfermedad de transmisión sexual que se sabe que causa cáncer cervical. También se analizó la infección por Chlamydia trachomatis, una enfermedad de transmisión sexual frecuente que podría constituir un cofactor de los PVH.

Métodos. La investigación, realizada en 1997 y 1998 en la zona fronteriza de los estados de Arizona (EE.UU.) y Sonora (México), consistió en un estudio transversal de 2436 mujeres (media de 33,3 \pm 10,3 años) que acudían a consultas ginecológicas de rutina. Se efectuaron frotis cervicales de Papanicolaou y pruebas de detección de la infección por PVH, mediante la reacción en cadena de la polimerasa (PCR) y la captación de híbridos $(\mathrm{HC})$, y de la infección por $C$. trachomatis, mediante $\mathrm{HC}$ e inmunoanálisis enzimático (EIA).

Resultados. La prevalencia global de exámenes citológicos anormales fue del 9,3\%; la diferencia entre México $(11,4 \%)$ y EE.UU. $(6,6 \%)$ fue significativa. Un 14,5\% de las participantes fueron positivas para los PVH en la PCR, sin que hubiera diferencias entre los dos países, y esto a pesar de que las mujeres mejicanas tenían menores riesgos relacionados con la conducta. La prevalencia global de $C$. trachomatis fue mayor con la HC que con el EIA $(8,2 \%$ frente a $3,0 \%)$ y fue mayor en México que en EE.UU. con ambos métodos.

Conclusiones. Un importante logro de este proyecto consistió en la puesta en marcha de un programa de control de la calidad de la recolección de los frotis de Papanicolaou que dio lugar a una notable reducción de los frotis inadecuados en México. A pesar de numerosas posibles barreras logísticas, el equipo de los dos países consiguió realizar con éxito un estudio a gran escala en el área fronteriza y desarrollar la infraestructura para futuras investigaciones. 